\title{
FIELDS, DVLC AND PANRETINAL PHOTOCOAGULATION
}

\author{
S. A. BUCKLEY, L. JENKINS, L. BENJAMIN \\ Aylesbury
}

\begin{abstract}
SUMMARY
Laser panretinal photocoagulation (PRP) reduces visual loss in proliferative diabetic retinopathy but decreases peripheral retinal function. The Driver and Vehicle Licensing Centre (DVLC) states that when a patient volunteers that he or she has had photocoagulation, a questionnaire will then be sent to the patient's diabetic physician who can refer the patient for formal field testing. Of 30 patients who had PRP, 15 failed DVLC visual field regulations using the Esterman binocular field test on the Humphrey field analyser. The failures were more likely to have had treatment with a xenon laser, but there was no difference between the groups as regards age, number of burns or whether an argon or diode laser was used. The patients who failed were more likely to be hypertensive $(p=0.04)$. Two patients with unilateral PRP could not meet the driving regulations because of other field defects. Diabetes itself causes field defects, and therefore even with small amounts of laser, formal field testing may be necessary.
\end{abstract}

Laser panretinal photocoagulation (PRP) is known to reduce the risk of severe visual loss in diabetic proliferative retinopathy. ${ }^{1}$ However, PRP causes visual field loss and reduced peripheral retinal function., ${ }^{2,3}$ Driver and Vehicle Licensing Centre (DVLC) regulations now require a diabetic who has had laser treatment to have a binocular visual field of $120^{\circ}$ along the horizontal with $20^{\circ}$ above and below this horizontal line. The fields can be done on a variety of perimeters, either kinetic or static. Guidelines have been issued by the DVLC as to the parameters needed for each type of field testing equipment used. $^{4}$

\section{METHOD}

Thirty diabetics who had had full PRP with either a xenon arc, argon or diode laser, or combinations of these modalities, had their fields tested on the Humphrey field analyser, an automated static perimeter. The program used was the Esterman binocular field program which assessed the binocular visual field in accordance with DVLC regulations. ${ }^{4}$

Correspondence to: S. A. Buckley, FCOphth, DO, Registrar Ophthalmology, Stoke Mandeville Hospital, Aylesbury HP21 8AL, UK.
All patients had had laser treatment at least 2 months previously and all were considered to have had successful regression of their proliferative retinopathy. Any patients who failed were given a second test a few weeks later, to allow for any learning or fatigue effect. ${ }^{5}$ Patients who were unexpected failures also had uniocular full visual field analysis to analyse why they had failed. The two groups of patients, those that failed and those that passed, were then looked at in terms of laser type, number and size of burns, choroidal pigmentation, sex, age, diabetic age, insulin dependence, blood pressure, nephropathy and neuropathy, to see whether any factors affected which group a patient was likely to fall into. Choroidal pigmentation was assessed by grading fundus photographs taken prior to PRP from 1 to 5, with 1 being a 'blond' fundus and 5 a heavily pigmented fundus. Patients were considered to be hypertensive if they were either taking antihypertensive drugs or had consistent blood pressure measurements equal to or greater than $150 / 90 \mathrm{mmHg}$, the level usually used to define adult hypertension. ${ }^{6}$ Nephropathy was present if the patient had either proteinuria, a raised creatinine level or a kidney transplant. Absent reflexes, loss of vibration sense or autonomic problems indicated diabetic neuropathy.

\section{RESULTS}

Of the 30 PRP patients, 15 failed the Humphrey binocular driving field test. Most had a reasonable horizontal field of up to $80^{\circ}$, but outside this those that failed could not achieve the required $20^{\circ}$ of visual field above and below the horizontal. A certain amount of leniency was applied, with the patient being passed when isolated scotomas just prevented the full width of the required field being obtained. If these cases were also to have been considered failures, then the total failures would have been 19 out of 30 patients, ie $63 \%$.

There was no statistically significant difference between the two groups regarding any of the systemic factors listed in Table I with the exception of blood pressure. There was an increased chance of failure in patients who either had blood pressure readings over $150 / 90 \mathrm{mmHg}$ or were on antihypertensive treatment $(p=0.04)$. This was less likely when only those with blood pressure greater than $150 / 90 \mathrm{mmHg}$ were considered $(p=0.08)$. 
Table I. Systemic factors in the groups who passed and failed the DVLC field regulations

\begin{tabular}{|c|c|c|c|}
\hline Factor & Passed & Failed & Significance \\
\hline Mean age (yr) & 48.4 & 53.4 & $p=0.30$ \\
\hline Mean diabetic age (yr) & 24 & 22 & $p=0.57$ \\
\hline $\begin{array}{l}\text { Non-insulin-dependent vs. } \\
\text { insulin-dependent }\end{array}$ & $3: 12$ & $4: 11$ & $p=0.45$ \\
\hline Neuropathy & $5 / 15$ & $6 / 15$ & $p=0.54$ \\
\hline Nephropathy & $2 / 15$ & $2 / 15$ & $p=1.00$ \\
\hline Hypertension $^{\mathrm{a}}$ & $4 / 15$ & $10 / 15$ & $p=0.04$ \\
\hline Hypertension, no xenon ${ }^{a}$ & $4 / 14$ & $8 / 11$ & $p=0.04$ \\
\hline Treated hypertension & $2 / 15$ & $4 / 15$ & $p=0.39$ \\
\hline Blood pressure $>150 / 90 \mathrm{mmHg}$ & $4 / 15$ & $9 / 15$ & $p=0.08$ \\
\hline
\end{tabular}

${ }^{a}$ The definition of hypertension in these groups included patients on antihypertensive therapy, and also those who had a blood pressure equal to or more than $150 / 90 \mathrm{mmHg}$ on three consecutive occasions.

Table II. Comparison of the argon and diode laser treatments used in the groups who passed and failed the DVLC field regulations

\begin{tabular}{lccc}
\hline & Passed & Failed & Significance \\
\hline $\begin{array}{l}\text { Mean totals and range } \\
\text { of laser burns per } \\
\text { patient, excluding } \\
\text { xenon }\end{array}$ & $\begin{array}{c}3195 \\
(1464-5917)\end{array}$ & $\begin{array}{c}3608 \\
(1560-6088)\end{array}$ & $p=0.54$ \\
$\begin{array}{l}\text { Proportion of argon to } \\
\text { diode in the } \\
\text { combination-treated } \\
\text { eyes }\end{array}$ & $\begin{array}{c}\text { Argon 53\%, } \\
\text { diode 47\% }\end{array}$ & $\begin{array}{c}\text { Argon 45\%, } \\
\text { diode 55\% }\end{array}$ & $p=0.70$ \\
$\begin{array}{l}\text { Mean totals of argon } \\
\text { and diode burns in the } \\
\text { combination-treated } \\
\text { eyeș }\end{array}$ & $\begin{array}{c}\text { Argon 1089, } \\
\text { diode 983 }\end{array}$ & $\begin{array}{c}\text { Argon 1304, } \\
\text { diode 1586 }\end{array}$ & $p=0.49$ \\
$\begin{array}{l}\text { Choroidal } \\
\text { pigmentation graded }\end{array}$ & 3.2 & 3.07 & $p=0.54$ \\
$\begin{array}{l}\text { - } 5 \text { (see text) } \\
\text { Mean burn size }\end{array}$ & $426 \mu \mathrm{m}$ & $429 \mu \mathrm{m}$ & $p=0.84$ \\
\hline
\end{tabular}

Five patients had had xenon treatment, and of these 4 failed and 1 passed. Excluding the xenon-treated patients, there was no difference in the total number of laser burns given or the average burn size. There was also no difference between the two groups in the relative proportions and number of burns of diode or argon used (Table II). Twenty-six eyes had been treated with argon alone. Not enough patients had been treated by diode alone to allow direct comparisons, but 16 eyes had been treated with $50 \%$ diode and 50\% argon. On average it took 1832 argon burns to induce regression compared with 2430 of the argon/ diode combination. This was not a statistically significant difference $(p=0.18)$.

Of the 15 diabetics who passed DVLC regulations, 12 had had bilateral PRP and 3 unilateral. Of the 15 who failed, 13 had had bilateral PRP and 2 unilateral. In all the failures where only one eye had been lasered, the patients were unable to complete the binocular field test successfully because of field defects documented on full peripheral field analysis in the other eye.

\section{DISCUSSION}

Xenon arc, diode and argon laser are the three methods of photocoagulation used in the diabetics assessed. Xenon arc emits white light from 350 to $1600 \mathrm{~nm}$ which is absorbed well by melanin. Argon laser emits a beam between 488 and $514 \mathrm{~nm}$ whereas diode laser is between 805 and $811 \mathrm{~nm}$. Xenon and argon photocoagulation have been proved to reduce the risk of visual loss in proliferative retinopathy. ${ }^{1}$ Diode laser is also effective in causing regression of new vessels. ${ }^{7,8}$ Analysis of our results supports the view that treatment with a diode laser is probably just as effective as with argon, since the number of burns required to cause regression is statistically similar whatever the laser type.

Four of 5 xenon arc patients failed the field requirements. Moderate to heavy xenon treatment can result in severe retinal damage, with the heaviest burns histopathologically showing total retinal destruction with loss of all retinal layers. Light xenon treatment results in changes limited to the retinal pigment epithelium and the choriocapillaris, leaving the inner retinal layers intact. ${ }^{9}$ This explains why xenon arc lasers can cause severe field loss and in one patient limited the visual field to the central $20^{\circ}$ only.

Comparisons of the groups who passed and failed the field test show no difference between groups in the number of argon and diode burns or the burn size. A factor which can not be assessed directly is the severity of the burns at time of PRP. It is known that visual field loss is more prevalent in eyes treated with intense spots of high energy when compared with eyes treated with similarsized moderate burns. ${ }^{10}$

In our two groups there is an equal scatter of blond to pigmented fundi, with apparently no relationship to visual field outcome. This suggests that despite the greater difficulty in obtaining visible burns in blond fundi, there is no associated increased risk of visual field loss. Excluding patients who had had xenon treatment, since this is a known risk factor for field loss, there is a greater incidence of hypertension in those patients who failed the DVLC regulations $(p=0.04)$. However, it must be borne in mind that this is a small sample and further studies will be needed to confirm these findings.

Two patients could not fulfil the DVLC criteria despite having only one eye lasered. This is due to profound field defects in the lasered eye combined with previously unknown defects, superiorly and nasally, in the nonlasered eye. Other studies have shown that even with at most moderate retinopathy and no laser treatment, diabetics can lose significant visual field presumably secondary to subclinical microangiopathy. ${ }^{11}$ Several studies indicate an association between hypertension and the development and progression of diabetic retinopathy. ${ }^{12}$ The field defects in our patients may have been present to some degree prior to laser treatment.

Field loss is probably multifactorial and it should not be assumed that just because a patient has had only one eye lasered, or even has had no laser treatment at all, that he or she will fulfil the legal driving requirements without formal field testing.

Key words: Diabetic retinopathy, Panretinal photocoagulation, Visual fields. 


\section{REFERENCES}

1. The Diabetic Retinopathy Research Group: Photocoagulation treatment of proliferative diabetic retinoapathy: the second report of diabetic retinopathy study findings. Ophthalmology 1978, 85: 82-106.

2. Sieberth V, Alexandrides E, Feng W: Function of the diabetic retina after panretinal argon laser coagulation. Graefes Arch Clin Exp Ophthalmol 1987, 225: 385-90.

3. Zaluski S, Marcil G, Lamer L, Lambert J: Study of the visual field using automated static perimetry following PRP in the diabetic. J Fr Ophtalmol 1986, 9: 395-401.

4. Munton G: Form CLE 1060. DVLC Drivers Medical Branch, September 1988.

5. Kulze JC, Stewart WC, Sutherland SE: Factors associated with a learning effect in glaucoma patients using automated perimetry. Acta Ophthalmol (Copenh) 1990, 68: 681-6.

6. Sleight P: Oxford Textbook of Medicine. Oxford University Press, 1987: 360-81.

7. Balles M, Puliafito C, D’Amico D, Jacobson J, Bamgruber
$\mathrm{R}$ : Semiconductor diode laser photocoagulation in retinal vascular disease. Ophthalmology 1990, 97: 1553-60.

8. McHughJDA, Marshall J, ffytche TJ, Hamilton AM, Raven A, Keeler CR: Initial clinical experience using a diode laser in the treatment of retinal vascular disease. Eye 1989, 3: 516-27.

9. Tso M, Wallow I, Elgin S: Experimental photocoagulation of the human retina. Arch Ophthalmol 1977, 85: 1035-40.

10. Seiberth V, Alexandridis E: Function of the diabetic retina after panretinal argon laser photocoagulation: influence of the intensity of the coagulation spots. Ophthalmologica 1991, 202: 10-7.

11. Trick GL, Trick LR, Kilo C: Visual field defects in patients with insulin-dependent and non-insulin-dependent diabetes. Ophthalmology 1990, 97: 475-82.

12. Parving HH: Impact of blood pressure and antihypertensive treatment on incipient and overt nephropathy, retinopathy and endothelial permeability in diabetes mellitus. Diabetes Care 1991, 14: 260-9. 